\title{
Homicídio Juvenil: Papel da Polícia/Justiça Criminal Brasileira na Visão de Famílias Enlutadas ${ }^{1}$
}

\author{
Daniela Fontoura Domingues** \\ Universidade de Brasília, Brasília, DF, Brasil \\ Maria Auxiliadora Dessen \\ Universidade Católica do Salvador, Salvador, BA, Brasil
}

\begin{abstract}
RESUMO
Diferentemente das perdas naturais, os óbitos decorrentes de homicídios envolvem instâncias jurídicas, cuja função é elucidar os episódios e punir o(s) culpado(s). Este estudo apresenta a percepção sobre o papel da polícia/justiça de mães e irmãos de jovens vítimas de homicídio por arma de fogo. Participaram da pesquisa oito famílias que responderam a um questionário de caracterização do sistema familiar e a um roteiro de entrevista semiestruturada. Os relatos foram submetidos à análise qualitativa. Os dados enfatizam a frustração dos participantes quanto ao desempenho do Estado na apuração dos delitos e na prisão dos perpetradores, com a falta de punição gerando uma profunda insatisfação nos familiares. Os resultados sugerem a necessidade de mudanças no sistema judiciário brasileiro.
\end{abstract}

Palavras-chave: homicídio juvenil; impunidade; família; polícia; justiça criminal.

\begin{abstract}
Juvenile Homicide: The Role of the Brazilian Police/Criminal Justice in Mourning Families

Unlike natural losses, deaths caused by murders involve a legal body of people whose function is to elucidate the episode and to punish the culprit(s). This study presents the mothers' and siblings' perceptions about the role of the police/criminal justice after losing a young family member due to homicide by firearm. The participants were eight families who answered a questionnaire about the characterization of the family system and a semi-structured interview. The reports were submitted to the qualitative analysis. The results emphasize the frustration of the participants regarding to the performance of the State to solve the crimes and to apprehend the perpetrators; and the lack of punishment generates a deep dissatisfaction among the relatives. The results indicate the necessity of changing the laws in Brazil.

Keywords: juvenile homicide; impunity; family; police; criminal justice.
\end{abstract}

No mundo contemporâneo, a violência e, sobretudo, a vitimização de jovens por homicídio constitui um fenômeno complexo que afeta as sociedades e, consequentemente, milhares de famílias (Cano \& Ribeiro, 2007). O principal grupo de vítimas são "moradores de grandes centros urbanos, do sexo masculino, negros ou pardos, com idades variando entre 15 e 24 anos, baixa escolaridade e renda, feridos por arma de fogo e mortos em via pública" (Zilli \& Vargas, 2013, p. 622). A maioria das vítimas de disparo por armas de fogo em 2012 foi de negros, um número 2,5 vezes maior do que de brancos, para cada grupo de $100 \mathrm{mil}$ habitantes (Waiselfisz, 2015).
As estatísticas brasileiras revelam que, no conjunto da população, a taxa de mortes por arma de fogo passou de 7,3 por 100 mil habitantes, em 1980, para 21,9 em 2012, havendo um crescimento de $387 \%$, quando a população brasileira cresceu em torno de $61 \%$ (Waiselfisz, 2015). Enquanto em 1980, os homicídios representavam, em média, $70 \%$ do total de mortes por arma de fogo, em 2012, eles passaram a representar a quase totalidade das mortes, isto é, 94,5\%. Neste quadro, os homicídios juvenis entre jovens de 15-29 anos registraram um crescimento alarmante, em torno de $400 \%$, passando de 12,8 mortes por 100 mil habitantes, em 1980, para 47,6 em 2012.

\footnotetext{
* Endereço para correspondência: Daniela Fontoura Domingues - danydom61@gmail.com
} 
O Mapa da Violência 2015 (Waiselfisz, 2015) aponta, em números absolutos, 42.416 mortes por arma de fogo no Brasil, em 2012, isto é, 116 óbitos por dia, destacando que este número está bem acima da quantidade de vítimas de 40 dos conflitos armados que assola o mundo atual. Tais mortes dizem respeito a todos os estados da federação, sem exceção, sendo Alagoas, o estado líder nas taxas deste tipo de homicídio (156,4 vítimas por 100 mil habitantes), seguido por: Espírito Santo, Ceará, Bahia e Paraíba.

Políticas no campo da saúde pública e da educação apontam um decréscimo na mortalidade infantil nas últimas décadas. Entretanto, o mesmo não vem ocorrendo em relação às mortes por homicídio (Peres, Cardia, \& Santos, 2006), cujos índices tiveram um breve retrocesso entre 2003 e 2007, época das campanhas de desarmamento, mas logo voltaram a crescer (Waiselfisz, 2013a), atingindo números epidêmicos em 2012, conforme mostra o Mapa da Violência 2015 (Waiselfisz, 2015). Estas estatísticas têm levado os gestores de políticas públicas a refletirem sobre o panorama atual e têm, também, instigado o planejamento e a implementação de trabalhos direcionados a dirimir este grave problema social (Brasil, 2008).

O aumento da consciência dos direitos do cidadão e a alteração no perfil dos óbitos têm despertado o interesse por novos estudos, tanto do ponto de vista micro como macrossocial (Gawryszewski, Koizumi, $\&$ Mello-Jorge, 2004). Independentemente da perspectiva adotada, a maioria dos estudos sobre o tema sustenta que as condições de pobreza estão necessariamente associadas às taxas de mortalidade juvenil por causas violentas (Waiselfisz, 2007, 2008, 2013a, 2013b). No entanto, os indicadores do Índice de Desenvolvimento Humano, que levam em consideração aspectos como longevidade e educação (PNUD, 2010), acrescidos de variáveis de concentração de renda e do índice de Gini, vêm demonstrando que os homicídios estão mais associados às disparidades na distribuição de renda (Waiselfisz, 2008) do que à pobreza em si.

Este fato pode ser observado em cidades como Brasília, Belo Horizonte e Fortaleza, cujo coeficiente de Gini está acima de 0,60 (UN-Habitat, 2008). O índice Gini é uma medida de concentração de renda que varia de zero a 1 , com zero indicando que todos os indivíduos têm participação igualitária em termos de distribuição de renda, enquanto 1 aponta para uma maior concentração de um determinado grupo de indivíduos.

Além do fator distribuição de renda, há outros aspectos relacionados ao fenômeno da violência e, sobretudo, aos óbitos por homicídio. No Distrito Federal, assim como em outras localidades, as diferenças socioespaciais têm uma parcela de contribuição, bem como a ausência de serviços adequados, de benfeitorias e de infraestrutura (Vasconcelos \& Costa, 2005). Na capital do país, a remoção das pessoas de baixa renda para locais afastados e distantes da área central, na fase de edificação da cidade, gerou um processo de urbanização marginal caracterizado pela falta de infraestrutura adequada para acolher os migrantes oriundos de diversas partes do território nacional (Ferreira \& Penna, 2005; Gouvêa, 2005).

Segundo Porto (2010), a substituição do universo rural pelo urbano representa "uma fragmentação valorativa considerável, uma desestruturação das formas tradicionais de solidariedade e dos laços sociais ancorados, por exemplo, em redes de parentesco, próprias ao mundo agrário" (p. 103). Neste contexto, a fragilidade nas relações familiares e as alterações nos sistemas de valores e crenças podem potencializar ambientes adversos e colaborar para as situações de conflito (Barber-Madden, \& Saber, 2010), bem como influir nas percepções dos indivíduos e dos grupos acerca da realidade social.

A deterioração da qualidade de vida tem colaborado para incrementar as taxas de criminalidade (Gouvêa, 2005) e, por conseguinte, sentimentos coletivos de desamparo e vulnerabilidade (Soares, Miranda, \& Borges, 2006). O medo desencadeado pelas inúmeras manifestações da violência acaba por produzir novas composições de sociabilidade e, consequentemente, alterações nos comportamentos e no modo de agir das pessoas (Baierl, 2004).

De acordo com Adorno e Pasinato (2010), nos dias atuais, não é rara a sensação de medo e insegurança explicitada pela população. Para esses autores, tais manifestações "revelam fortes descrenças nas instituições da sociedade democrática encarregadas de aplicar lei e ordem, proteger os direitos civis dos cidadãos, consagrados na Constituição, em particular o direito à segurança" (p. 38). No que se refere às famílias acometidas pela violência e, em especial, aquelas que enfrentam a perda de um ente por homicídio, a elucidação do crime e a punição dos culpados são 
medidas esperadas pelos sobreviventes (Gekoski, Adler, \& Gray, 2013; Salloum \& Rynearson, 2006). Entretanto, quando têm frustradas suas expectativas no sistema de justiça criminal, sentem-se duplamente atingidos e estigmatizados (Sharpe, 2015; Spungen, 1998), em geral, pela falta de uma resposta plausível ao episódio (Lohan \& Murphy, 2002).

Trabalho recente empreendido por Mastrocinque et al. (2014) revela que há uma imensa insatisfação quanto às notícias oriundas do sistema de justiça criminal. A inabilidade dos profissionais para lidar com os enlutados, o emprego de linguagem demasiadamente técnica, formal e sem empatia são as principais conclusões dos autores. Uma pesquisa qualitativa realizada no Reino Unido, com 41 pessoas em processo de luto decorrente de perdas por homicídio, aponta que as principais reclamações dirigidas às instâncias de justiça dizem respeito à falta de informações e à comunicação pouco cuidadosa sobre o episódio, por parte dos agentes policiais (Malone, 2007). Além disso, o estudo revela que os familiares nutrem a expectativa de que o responsável pelo crime seja, logo, encarcerado e condenado, fato que na prática não se concretiza.

De acordo com Carvalho Filho (2004), para cada infração cometida, há uma punição, e se o infrator não é por ela alcançado - seja por inabilidade na apuração dos fatos ou fuga, entre outros motivos - o crime permanece impune. Apesar de competir ao Estado fornecer uma resposta às ações delituosas e aplicar medidas eficazes para evitar delitos, a polícia e a Justiça nem sempre conseguem conter os crimes e, tampouco, aplicar as leis.

As agências policiais têm, entre outras funções, o papel de promover a investigação; porém, “em todo o mundo, a investigação cobre tão somente parte das ocorrências que chegam ao conhecimento da autoridade policial" (Adorno \& Pasinato, 2010, p. 57). Segundo Zilli e Vargas (2013), a apuração dos casos de homicídio resulta de uma cadeia de evidências bem alicerçada e de um conjunto probatório organizado, diferentemente dos demais delitos. A investigação dos crimes envolve também uma série de sentimentos, relações e dinâmicas, o que torna a elucidação dos episódios ainda mais delicada.

A atuação da polícia depende do sistema de justiça criminal que, muitas vezes, é inadequado e ineficaz. Para o imaginário popular, tal vinculação impede a distinção entre o trabalho que a polícia executa e o sistema de justiça como um todo (Goldstein, 2003). Portanto, no que tange às ações contra o crime, parece existir uma sobreposição de explicações para o fenômeno da impunidade. Cerqueira, Lobão e Carvalho (2007), por exemplo, atribuem a falência do combate ao crime no Brasil ao modelo arcaico de polícia e à falta de polícia técnica e de investigação. Existem poucos dados a respeito do esclarecimento dos delitos no país, seja pela falta de estudos sobre o tema, seja pela precariedade no sistema de registro e informatização da justiça criminal (Lemgruber, 2001). Segundo Waiselfisz (2013a), o elevado índice de impunidade contribui para a manutenção da violência homicida como forma de resolução de conflitos, uma vez que o perpetrador tem baixo risco de ser identificado, apanhado e condenado.

Estudo efetuado na cidade do Rio de Janeiro (Cano, 2006) indica que apenas $10 \%$ dos crimes de homicídio recebem punição, o que mostra a ineficácia do sistema. A não efetividade da Justiça, por sua vez, pode favorecer espaços para arbitrariedades, transgressões, caos e violência (Porto, 2010). E os sobreviventes, frequentemente, decepcionados diante das expectativas de punição, tendem a acreditar que há uma falta de legislação compatível aos crimes, passando a reivindicar o recrudescimento das leis. Assim, há uma propensão "a deslocar a ênfase, privilegiando a elaboração das leis, mais do que seu efetivo cumprimento [...]" (Porto, 2010, p. 278).

Do ponto de vista social, as autoridades competentes devem trabalhar para esclarecer o delito, dar um retorno à comunidade e, sobretudo, à família, que necessita construir uma rede de significados para o ato, rever seus valores e crenças e prosseguir em sua trajetória de vida (Armour, 2002; Mastrocinque et al., 2014; Salloum \& Rynearson, 2006). O cumprimento das leis, mesmo com suas deficiências e lacunas, é fator primordial para que a população se sinta segura e protegida. Como salientado por Soares et al. (2006), há uma grande dificuldade de as pessoas confiarem nas instituições públicas designadas a protegê-las e ampará-las. A pesquisa realizada pelos autores, com 690 vítimas da violência na capital fluminense, evidenciou que há um descrédito geral, tanto do papel da polícia/justiça como do próprio sistema penitenciário e dos representantes do governo. O estudo enfatiza, ainda, que os sobreviventes das situações de violência precisam de respeito, apoio e, principalmente, visibi- 
lidade, pois esses fatores influenciam no surgimento de enfermidades físicas e emocionais.

Gekoski et al. (2013), dedicados a estudar a vitimização secundária em covítimas de homicídio, recomendam às instâncias judiciais uma capacitação permanente dos profissionais que lidam com esse público e uma ampla divulgação sobre o papel de cada instituição no desfecho dos casos. Essas medidas, de acordo com os autores, resultariam em uma redução no nível de estresse e nos sentimentos de frustração, de raiva e desapontamento gerados no decorrer dos processos. Tais efeitos seriam benéficos particularmente para a família, que tem o seu funcionamento alterado, necessitando de uma ampla reorganização (Domingues, Dessen, \& Villas-Boas, 2011). Bussinger (2010) também evidencia, após pesquisa realizada com mulheres que perderam filhos de forma violenta, que a família se sente impotente e incompreendida ante as adversidades e a morte do seu ente querido, necessitando de ajuda profissional.

A situação das famílias no Distrito Federal é bastante séria, conforme aponta os dados do Mapa da Violência 2015 (Waiselfisz, 2015). Entre as capitais, Brasília ocupa a $17^{\mathrm{a}}$ posição no ordenamento da menor para a maior taxa de mortalidade por arma de fogo na população geral, embora, em se tratando da população jovem, ocupe a $11^{\text {a }}$ posição. No entanto, de 2002 a 2012 , houve um crescimento de $12,7 \%$ das taxas de óbito entre os jovens na capital brasileira, com números alarmantes entre 2011 e 2012, cujo crescimento foi da ordem de $8,8 \%$. Assim, este estudo visa descrever o que pensam as famílias enlutadas da capital federal a respeito do papel da polícia/justiça em situações de perda de um filho ou irmão, em razão de homicídio por arma de fogo e se há diferenças em suas percepções quando os jovens vitimados apresentavam ou não comportamentos transgressores antes dos homicídios.

\section{MÉTODO}

\section{As famílias e os jovens vitimados}

Participaram do estudo oito famílias, sendo uma pessoa do sistema parental (M: mãe; $n=8$ ) e outra do fraternal (I: irmão; $n=5$ ). As famílias em que o jovem falecido era o único filho $(n=2)$, ou que o irmão não pode participar $(n=1)$, tiveram, exclusivamente, a adesão da genitora. Todas as famílias eram proceden- tes de regiões periféricas do Distrito Federal, de nível socioeconômico baixo, e estavam vivenciando a perda de um jovem (filho/irmão) vitimado por homicídio por arma de fogo. A coleta de dados ocorreu entre o primeiro e o $12^{\circ}$ mês após o episódio.

Os jovens vitimados $(n=8)$ tinham em média 18,7 anos. A maior parte deles era do sexo masculino $(n=7)$, de raça parda e não havia completado o ensino fundamental. Em relação à ocupação, dois foram considerados "sem ocupação"; os demais frequentavam a escola ou desenvolviam atividade laboral esporádica. Dos oito jovens, apenas um havia deixado dependentes (filhos), sendo esta a única vítima do sexo feminino.

Em razão das circunstâncias ambientais implicadas nos homicídios, como tráfico de drogas e disputas entre gangues, algumas famílias foram indicadas por pessoas que pertenciam a organizações não governamentais (ONGs) e/ou que atuavam na prevenção da violência no Distrito Federal, enquanto outras foram selecionadas por profissionais da área do Direito e da Psicologia compondo, portanto, uma amostra por conveniência. Das 16 famílias convidadas, apenas 8 aderiram à pesquisa. $\mathrm{O}$ principal motivo alegado para a recusa foi a falta de condições emocionais e psicológicas dos familiares. $\mathrm{O}$ segundo motivo relatado foi o temor de represálias, em virtude de alguns perpetradores dos homicídios não estarem encarcerados, por ocasião da realização do estudo.

\section{Procedimentos para a coleta de dados}

A coleta de dados ocorreu na residência dos participantes, após aprovação do Comitê de Ética da Universidade de Brasília (UnB), cujo projeto foi inscrito sob o número 179/2008. Foram aplicados dois instrumentos: (a) o Questionário de Caracterização do Sistema Familiar (Dessen, 2009), respondido pelas mães, incluindo perguntas sobre idade, nível de escolaridade e ocupação dos participantes, além de questões específicas sobre as relações familiares e sobre aspectos de infraestrutura e recursos disponíveis aos moradores das comunidades; (b) um roteiro de entrevista semiestruturada, respondido pelas mães e irmãos, abordando os seguintes temas: circunstâncias dos homicídios, impacto da perda na organização familiar, rede social de apoio, padrões de comunicação na família, bem como valores e expectativas dos familiares para a vida futura. No entanto, os participantes abordaram, espontaneamente, dados relativos: à violência e à segurança 
no local de residência; à atuação e ao papel da Justiça/polícia por ocasião do homicídio; e aos valores, às crenças e às expectativas quanto à aplicação das leis, que são objeto de análise neste artigo.

Os dados do Questionário de Caracterização do Sistema Familiar foram tabulados e as entrevistas gravadas em áudio, com duração média de duas horas, foram digitalizadas e, posteriormente, transcritas, na íntegra. Todas as verbalizações foram submetidas à técnica de Análise de Conteúdo (Bardin, 1977) e, em seguida, o material passou por uma categorização, conforme os passos de construção de sistemas de categorias, proposto por Dessen e Cerqueira-Silva (2009).

Este procedimento envolveu quatro etapas, a saber: (a) seleção e exploração do material (pré-análise); (b) codificação; (c) agrupamento e reagrupamento de temas; e (d) definição das categorias empíricas (tratamento, inferência e interpretação). As verbalizações foram selecionadas pelo critério de similaridade entre os temas, dando origem a categorias embasadas nos princípios de exclusão mútua, homogeneidade e pertinência, evitando a repetição de assuntos em categorias distintas.

\section{RESULTADOS}

As famílias foram divididas em dois grupos: Grupo A e Grupo B. O Grupo A é composto por famílias (F3, F4, F5, F7 e F8) cujos jovens apresentavam comportamentos transgressores antes dos homicídios e, o Grupo B, por famílias (F1, F2 e F6) em que os jovens não tinham antecedentes dessa natureza, segundo declarações dos familiares. A divisão em grupos distintos é baseada na própria postura adotada pela polícia/justiça, tornando as duas categorias - com e sem antecedentes transgressores - uma forma rotineira de lidar com os homicídios juvenis. Além disso, é importante verificar se a percepção dos familiares difere, quando se leva em conta esta variável. Foram considerados comportamentos transgressores, para fins desse estudo, o envolvimento em furtos, roubos, cumprimento de medida socioeducativa ou prisão, tráfico de entorpecentes, uso/abuso de álcool e de drogas. Os resultados, a seguir, são apresentados em duas grandes categorias: (a) atuação e papel da polícia/justiça póshomicídio; (b) atuação geral da polícia/justiça na sociedade e perspectiva de mudanças.

\section{Atuação e papel da polícia/justiça pós-homicídio}

No que diz respeito à atuação da polícia/justiça no homicídio, apenas duas famílias (F2 e F6), ambas do Grupo B, cujas vítimas não tinham comportamento transgressor, relataram ser eficiente a atuação da instituição. A eficiência foi atribuída à captura do perpetrador, conforme ilustram as falas: $E$ os três estão presos e vão ser julgados (M2). I Ele [perpetrador] tá preso... (M6). Em contrapartida, a ineficiência da polícia/justiça, destacada por 4 famílias (F1, F3, F7 e F8), foi atribuída ao fato de o perpetrador não ter sido preso ou ter sido encarcerado e, pouco tempo depois, posto em liberdade. Eles prendem [a polícia], a justiça solta. O juiz lá... solta. Sabe, o menor fica preso 45 dias. Nem sei se o [assassino] do R. tá preso até hoje, o que tirou a vida do meu filho (M1). I O rapaz que matou ele, tá aí solto. Ele ficou preso parece que só 8 dias, ou 9, 10 dias, uma coisa assim (M7). I Tá é solto! (M8). I O cara já tá solto. Pegou nem... Não ficou nem um mês dentro da cadeia. Como é que o cara matou o meu irmão, atirou num bocado de pessoa e não pegou... e nem tá preso!? (I7).

Outro motivo que contribuiu para a família considerar a atuação da polícia/justiça ineficiente foi a falta de feedback para os familiares sobre o crime (F1, F4 e F7). Ou seja, as famílias não receberam informações sobre o crime ou sobre a investigação. A Justiça não mandou ninguém aqui! Você não recebe um telefonema da, da polícia, do delegado, ninguém (M1). / Nunca veio ninguém aqui, ninguém, ninguém. Não veio investigador falar nada aqui pra nós. Não veio policial tomar informação. Aqui não veio ninguém, nem pra dizer assim... como é que ele morreu, se foi mesmo assim, como foi (M4). I Não tivemos satisfação de polícia. Se a gente quis saber, a gente foi lá na delegacia pegar a ocorrência (M7).

Por fim, a ausência de apoio à família dos jovens (F1 e F4) por parte da instituição também fez com que os participantes a avaliassem como ineficiente. A $\mathrm{fa}$ mília dele [perpetrador], eu te garanto, que tem toda a proteção... de psicóloga... de tudo. Quem matou meu filho... te garanto que tem toda a assistência psicologicamente, e aqui não vieram ninguém! (M1). / Nunca os direitos humanos veio aqui. Nunca os direitos humanos foi lá no hospital visitar o meu irmão. A Justiça não te dá esse apoio (I1).

Portanto, o critério utilizado pelos participantes para avaliar a atuação da polícia/justiça foi a prisão/não 
prisão dos acusados e a falta de feedback e apoio aos familiares. Das 8 famílias, em apenas duas, o perpetrador do homicídio havia sido capturado pela polícia, e, neste caso, as vítimas não apresentavam comportamento transgressor, segundo relato dos entrevistados. Três famílias relataram não receber informações e apoio.

\section{Atuação geral da polícia/justiça na sociedade e expectativas de mudanças}

Além de julgarem a atuação da polícia/justiça no homicídio como ineficiente, as famílias (F1, F4, F5, F6, F7 e F8) a julgaram como ineficiente em outros tipos de atuação: Nós não temos justiça no nosso Brasil (M1). / A Justiça pra mim não está com nada! É a pior que pode existir (M4). I A Justiça é um fracasso no Brasil! (I7). Elas forneceram algumas razões para explicar a ineficiência da Justiça/polícia. A primeira delas foi a corrupção: O problema é que a polícia, eu não digo todos, mas a maioria das polícias não prestam. A maioria das polícias, em vez de estar educando, corrigindo ou até mesmo prendendo quem precisa... estão metidos no próprio meio dessa sujeira (M4).

Para as famílias, além de corrupta, a polícia/justiça favorece a criminalidade, conforme relatado por 4 das 8 famílias (F1, F6, F7 e F8): A Justiça não é feita como deveria ser! A Justiça, hoje, contribui pra criminalidade! A Justiça favorece muito ao infrator. As autoridades são falhas, é a impunidade! (M7). I A nossa Justiça do Brasil, ela é falha em tudo. Enquanto tiver essa facilidade pro criminoso, só vai morrer cada dia mais... (M1). I Jovens, 'né', tem tanta facilidade em pegar em arma de fogo, 'né'? Esses rapazinhos, menininhos consegue pegar, 'né'? Com a maior facilidade... acho que está sendo muito fácil pra eles (M8). I A lei só beneficia os bandidos! [...]./ A Justiça? A Justiça do Brasil, vou ser sincera, é uma porcaria, [...] porque ele é réu primário, né, a qualquer momento ele pode estar solto. Ele tirou uma vida! Mas por causa dele ter os antecedentes bons, ele pode ser solto a qualquer momento. Que Justiça é essa?! (I6).

Duas outras razões foram atribuídas à ineficiência da polícia/justiça: (a) a desatualização das leis: A lei, a Justiça nesse país tão muito arcaica, tem que rever esse... penal, constitucional, civil... tudo. Tá muito arcaico (I1); e (b) a não recuperação das pessoas en- carceradas, por parte das políticas de reinserção social: Essas medidas socioeducativas não funcionam (M5). I Ela [prisão] só atinge os pobres mesmo. A Justiça... prisão, não recupera, 'né', quem entra lá sai fazendo... sai sabendo fazer mais coisas ainda [...]. Depois quando prende, eles mofam lá e eu não acho que deveria ser assim, sabe, por mais que... não sei, eu acho que eles tinham que se recuperar mesmo e... é isso (I5).

As famílias também emitiram sugestões para o bom funcionamento da polícia/justiça relacionadas, particularmente, à impunidade e à falta de resposta para os crimes. Uma família do Grupo B (F1) sugeriu o recrudescimento das leis: Se tivesse a lei, aqui no Brasil, da pena de morte, meu filho tava vivo. Sou a favor da pena de morte (M1). / Uma andorinha só não faz verão... [precisaria] uma mobilização... para mudar esse estatuto da criança e do adolescente (I1). Também foi citado por uma família (F4) a urgência de leis que atendam aos anseios da população: Precisaria as autoridades competentes, pensar melhor, fazer leis justas. Acho que a lei tem que refletir... fazer leis boas, lei decente. Fazer coisas que ajudem a pessoa a viver melhor (M4). As famílias de ambos os grupos que não se sentiram minimamente atendidas pela justiça relataram o desejo de que as leis fossem mudadas.

Sobre as razões para a existência de violência na sociedade, duas famílias (F2 e F7) a atribuíram à falta de investimentos em educação e em segurança: $S e o$ governo olhasse mais pelas crianças, pela educação delas, talvez não existiria tanta violência no mundo (M2). I Esses meninos vão pra vício... pra muita coisa que não deviam ir, por falta de educação (M7). I Os jovens de hoje em dia têm que ter a sua própria consciência de que usar uma arma é errado. De que tirar uma vida, é mais errado ainda (I2).

Duas famílias do Grupo A (F5 e F7) e todas as do Grupo B (F1, F2 e F6) enfatizaram a necessidade de investimentos em políticas públicas nas áreas da educação e da família. $O$ povo tão precisando apenas de educação. A base de tudo é a educação, é na escola, ter estudo, entendeu? Só isso que o povo precisa pra ter um futuro melhor. E o governo não tá nem aí pra isso (M2). / Nós, pais pobres, não conseguimos investir mais em educação; [precisa] investir mais em educação (M7). / Precisaria dar uma ênfase [atenção] na família (I1). I A rua não oferece nada; captar o jovem desde do... acho que... do primário, da primeira série. Ocupar o tempo deles com coisas educativas (I1). 
Independente das razões das mortes e da trajetória dos jovens, as famílias ressaltaram a necessidade de investimentos em educação, na família e em projetos e programas voltados à juventude. Eu acho que deviam ter mais projetos, mesmo... mais pra quem não pode pagar (I5), assim como em lazer e esporte. Os governantes deveriam dar mais algum... atividades pros jovens; ter uma quadra de esporte... (I1). / Deveria ter mais lazer no [...]. Lazer... é... coisas diferentes. Que toda vez que... toda vez que... é só isso aí, toda vez. [que tem uma] festa...é um no chão. Um, dois, três no chão. Toda vez é isso. Já tá virando rotina aqui. Todo final de semana... é um... [morto] naquela praça (I7).

\section{DISCUSSÃO}

As mortes violentas envolvem contextos e instituições incomuns às situações de perdas naturais e podem provocar reações intensas de dor, choque e perplexidade (Currier \& Neimeyer, 2006). As perdas decorrentes de acidentes automobilísticos, homicídios e suicídios têm consequências similares para o universo familiar, no que diz respeito à expressão de sintomas de estresse pós-traumático, às mudanças na visão de mundo dos pais e aos distúrbios nas relações sociais e interpessoais (Gekoski et al., 2013; Murphy, 2006).

Entretanto, diferentemente das outras situações de perda, os homicídios exigem a interferência do Estado na investigação, identificação, captura e punição dos responsáveis, sendo este um fator essencial à recuperação moral e psicológica dos sobreviventes (Salloum \& Rynearson, 2006). O luto dos parentes e amigos, portanto, envolve a elucidação dos fatos e o esclarecimento sobre os motivos do óbito. Se é negado aos familiares o direito de clarear dúvidas, confrontar informações e formular perguntas sobre o acontecimento, também é descartada uma parte importante do processo que implica reunir, de forma coerente, a história da pessoa falecida (Walsh, 2006).

Neste estudo, a falta de feedback sobre as circunstâncias do homicídio para as famílias foi um dos temas mais comentados. Quando a própria autoridade policial, imbuída em elucidar o episódio, não informa sobre as condições de morte da pessoa, ou não fornece explicações a respeito do ocorrido, aumenta a sensação de vazio e de fantasias acerca do crime, por parte dos familiares (Gekoski et al., 2013; Salloum \& Rynearson, 2006). A burocracia e as informações inconsistentes, peculiares ao Sistema de Justiça, dei- xam os familiares com a sensação de desamparo justamente no momento em que eles mais necessitam de respeito e solidariedade (Bussinger, 2010; Mastrocinque et al., 2014; Malone, 2007).

Neste estudo, a instituição não contribuiu para amenizar o sofrimento dos parentes e dos amigos das vítimas; pelo contrário, mostrou-se um poderoso fator de frustração e desapontamento, corroborando, assim, os dados da literatura (Bussinger, 2010; Malone, 2007; Mastrocinque et al., 2014; Sharpe, 2015; Spungen, 1998). Conforme salientam Salloum e Rynearson (2006), as mortes violentas demandam uma série de medidas judiciais e criminais que não incluem a família em suas instâncias e os sobreviventes se tornam expectadores da situação, não recebendo apoio ou satisfação do Estado. Além disso, poucos recursos e atendimentos são disponibilizados às famílias para minimizar os efeitos adversos dos episódios (Bussinger, 2010; Spungen, 1998).

Muitos sobreviventes de homicídios sentem-se negligenciados, marginalizados e invisíveis pela falta de suporte emocional e respaldo financeiro (Soares et al., 2006). De acordo com alguns participantes deste estudo, os parentes dos acusados dos delitos eram vistos de forma diferenciada pelas instâncias governamentais e não governamentais, que incluíam a visita de entidades dos direitos humanos às suas casas com o objetivo de oferecer conforto. Entretanto, este mesmo conforto não era oferecido a eles. A situação é agravada, também, pela impossibilidade de resguardo da família frente ao ato violento, devido ao assédio da mídia e dos procedimentos legais decorrentes da situação de homicídio (Soares et al., 2006; Spungen, 1998). A interferência judicial, policial e dos meios de comunicação em atos criminosos aumenta o risco de comprometer a saúde dos familiares pelo excesso de exposição e repetição desenfreada do assunto (Salloum \& Rynearson, 2006).

Ainda sobre a negligência da justiça, a maioria das famílias ressaltou aspectos relativos à corrupção, desatualização, colaboração à criminalidade e não recuperação dos condenados. A polícia/justiça foi avaliada como eficiente somente quando o acusado estava recolhido à prisão; por outro lado, a ineficiência foi destacada nos casos em que a polícia não havia conseguido encarcerar o criminoso, que se encontrava em liberdade. Todos os tópicos evidenciam a pouca confiança depositada no trabalho da polícia/justiça e nas medidas coercitivas. 
A sensação de impunidade parece colaborar para a descrença no papel da justiça, sugerindo que a não resolução dos crimes constitui também fator de risco para a reorganização das famílias vitimadas. Segundo Malone (2007), as frustrações relativas ao sistema de justiça criminal abrangem desde a comunicação com os advogados e se estendem até o julgamento e veredito final.

Quanto ao papel do Estado frente ao aumento da criminalidade no país, Cerqueira, Lobão e Carvalho (2007) consideram que há uma desestruturação geral do ofício de policial que inclui a desvalorização profissional da categoria, a falta de treinamento e capacitação, o corporativismo exacerbado, e a ausência de punição para os problemas de conduta. Assim, segundo eles, a polícia, que deveria promover ações de cidadania e estimular a paz, acaba sendo vista como um empecilho para avanços na área da segurança pública.

Neste sentido, parece existir um descompasso entre o que efetivamente a instituição policial realiza e aquilo que o cidadão espera que ela faça. Goldstein (2003) argumenta que para dirimir as arestas e as pressões sobre o desempenho da polícia na sociedade, deve-se "alinhar melhor as expectativas populares a uma avaliação acurada do que a polícia pode fazer, além de incrementar sua capacidade de suportar mais eficientemente as responsabilidades e aprimorar aqueles sistemas dos quais ela depende" (p. 27).

É provável que essas discrepâncias tenham contribuído para uma avaliação negativa dos participantes quanto ao desempenho da polícia na resolução dos crimes, independentemente se os jovens vitimados tinham ou não comportamento transgressor. Alguns familiares, por exemplo, exprimiram o desejo de ter leis mais severas, como a instauração da pena de morte no Brasil, e alterações no Estatuto da Criança e do Adolescente (ECA). Esse dado sugere que as ações policiais e judiciais, quando não são efetivas, instigam as famílias a buscarem no recrudescimento da lei uma alternativa às suas demandas. Portanto, a sociedade passa a reivindicar ações punitivas e legislação mais severa, relacionando a impunidade à insuficiência ou até a inexistência de leis (Porto, 2010).

Os participantes também teceram opiniões sobre as políticas públicas, destacando a necessidade de investimentos nas áreas de educação e família. Para eles, a juventude precisa de mais atenção e de projetos e programas de caráter educativo e gratuito, particularmen- te direcionados aos jovens de baixa-renda, visando oferecer oportunidades distintas daquelas encontradas nas ruas e no ócio. Reformulações na educação e no ensino são imprescindíveis, devendo abarcar tanto conteúdos ministrados em sala de aula como adaptações ao mercado de trabalho contemporâneo (BarberMadden \& Saber, 2010).

Os relatos fornecidos ao longo do estudo sugerem que as famílias necessitam de escuta, sobretudo pelo suporte insuficiente das instituições polícia/justiça e pela falta de um serviço de saúde especializado. O conteúdo dos relatos denota que os familiares carecem de espaço para colocar suas dúvidas, falar de suas angústias e reavaliar suas estratégias de sobrevivência. Ademais, alguns familiares demonstraram ter consciência de suas vulnerabilidades, da falta de respaldo da comunidade e da sociedade frente às perdas por homicídio.

Apesar dos avanços em várias dimensões da estrutura institucional - potencializados pelo processo de modernização democrática - a polícia brasileira ainda permanece como instituição burocrática e arcaica, desafiando todas as propostas e programas direcionados a reorganizar sua prática (Machado da Silva, 2011). Para mudar esse cenário, entre outras medidas, seria preciso uma transformação no próprio procedimento de investigação policial, desde a fase da denúncia até a instauração do processo e da sentença (Cano \& Ribeiro, 2007).

De acordo com Adorno e Pasinato (2010) “elevadas taxas de impunidade penal e desigualdade na distribuição de direitos e deveres reforçam o sentimento de insegurança coletiva, as suspeições contra as políticas de proteção dos direitos humanos, as desconfianças na capacidade e eficiência das instituições [...]" (p. 80). Coerente à posição dos autores, as famílias revelaram que a impunidade e a falta de respaldo aos seus anseios podem ser fatores de risco para a descrença no papel da Justiça e no cumprimento das leis. Além disso, a impunidade não deixa de ser um indicativo do enfraquecimento dos laços sociais, da pouca motivação para o exercício da cidadania e da solidariedade (Porto, 2010), tornando o universo e o futuro de diversas famílias brasileiras ainda mais obscuro e incerto.

A variedade de fatores implicados e a escassez de trabalhos dificultam a compreensão da precocidade das mortes e, por conseguinte, a implantação de programas efetivos (Cano \& Ribeiro, 2007). De qualquer forma, isto não constitui justificativa para a falta de 
investimentos em ações preventivas e intervenções pós-homicídio junto aos parentes, tanto das vítimas quanto dos acusados dos delitos. Além disso, é preciso incentivar a reflexão sobre os episódios. Tal medida contribui para o reconhecimento da dor, das adversidades enfrentadas pelos familiares, e auxilia na preservação da memória individual e coletiva deste grave problema em nossa sociedade (Bussinger, 2010).

Por tratar-se de um fenômeno complexo que perpassa as desigualdades na distribuição de renda e a questões sociais e culturais, a vitimização juvenil demanda a construção de ações, tanto no sentido de poupar vidas quanto de auxiliar as pessoas enlutadas a lidar com a perda (Waiselfisz, 2008, 2013b). Todavia, não há, até o momento, políticas de enfrentamento suficientes para reverter a situação, mesmo com a crescente divulgação e conscientização sobre o assunto (Waiselfisz, 2011, 2012, 2015). Para Waiselfisz (2015), é imprescindível que haja reformas no código penal atual, que favorece a impunidade. É preciso ainda investimentos em educação e melhoria nas condições de vida da população. Sem tais mudanças seria impossível combater os índices alarmantes e crescentes da violência e dos homicídios no Brasil.

\section{REFERÊNCIAS}

Adorno, S., \& Pasinato, W. (2010). Violência e impunidade penal: da criminalidade detectada à criminalidade investigada. Dilemas: Revista de Estudos de Conflito e Controle Social, 7, 51-84.

Armour, M. P. (2002). Journey of family members of homicide victims: A qualitative study of their posthomicide experience. American Journal of Orthopsychiatry, 72, 372-382.

Baierl, L. F. (2004). Medo social: da violência visível ao invisível da violência. São Paulo: Cortez.

Barber-Madden, R., \& Saber, B. A. (2010). A situação dos jovens no mundo. Em R. Barber-Madden \& T. F. Santos (Orgs.), A juventude brasileira no contexto atual e em cenário futuro (pp. 17-39). Brasília: UNFPA.

Bardin, L. (1977). Análise de conteúdo. Lisboa: Edições 70.

Brasil (2008). Violência: uma epidemia silenciosa, $17\left(1^{\mathrm{a}}\right.$ ed). Brasília: CONASS.

Bussinger, R. V. (2010). Nem que a morte os separe: trajetória de mães e filhos assassinados e representação social de Justiça. Curitiba: Juruá.

Cano, I. (2006). Mensurando a impunidade no Sistema de Justiça Criminal no Rio de Janeiro. Anais do III Con- gresso Latino-Americano de Ciência Política: Democracia e Desigualdades. Campinas, Unicamp.

Cano, I., \& Ribeiro E. (2007). Homicídios no Rio de Janeiro e no Brasil: dados, políticas públicas e perspectivas. Em M. V. G. Cruz \& E. C. Batitucci (Orgs.), Homicídios no Brasil (pp. 51-78). Rio de Janeiro: FGV.

Carvalho-Filho, L. F. (2004). Impunidade no Brasil - Colônia e Império. Estudos Avançados, 18, 181-194.

Cerqueira, D., Lobão, W., \& Carvalho, A. (2007). O jogo dos sete mitos e a miséria da segurança pública no Brasil. Em M. V. G. Cruz \& E. C. Batitucci (Orgs.), Homicídios no Brasil (pp. 141-176). Rio de Janeiro: FGV.

Currier, J. M., \& Neimeyer, R. A. (2006). Fragmented stories: The narrative integration of violent loss. Em E. K. Rynearson (Org.), Violent death: Resilience and intervention beyond the crisis (pp. 85-100). New York: Routledge.

Dessen, M. A. (2009). Questionário de caracterização do sistema familiar. Em L. Weber \& M. A. Dessen (Orgs.), Pesquisando a família: instrumentos para coleta e análise de dados (pp. 102-114). Curitiba: Juruá.

Dessen, M. A., \& Cerqueira-Silva, S. (2009). Desenvolvendo sistemas de categorias com dados de entrevistas. Em L. Weber \& M. A. Dessen (Orgs.), Pesquisando a família: instrumentos para coleta e análise de dados (pp. 4356). Curitiba: Juruá.

Domingues, D. F., Villas Boas, A. C. B. V., \& Dessen, M. A. (2011). Homicídio juvenil por arma de fogo e reorganização familiar: um estudo de caso. PSICO (PUCRS), 42, 51-58.

Ferreira, I. C. B., \& Penna, N. A. (2005). Território da violência. Em A. Paviani, I. C. B. Ferreira, \& F. F. P. Barreto (Orgs.), Brasília: dimensões da violência urbana (pp. 57-86). Brasília: UnB.

Gawryszewski, V. P., Koizumi, M. S., \& Mello-Jorge, M. H. P. (2004). As causas externas no Brasil no ano de 2004: comparando a mortalidade e a morbidade. Cadernos de Saúde Pública, 20, 995-1003.

Gekoski, A., Adler, J. R., \& Gray, J. M. (2013). Interviewing women bereaved by homicide: Reports of secondary victimization by the criminal justice system. International Review of Victimology, 19(3), 307-329.

Goldstein, H. (2003). Policiando uma sociedade livre. São Paulo: Edusp

Gouvêa, L. A. (2005). A violência estrutural. Em A. Paviani, I. C. B. Ferreira, \& F. F. P. Barreto (Orgs.), Brasília: dimensões da violência urbana (pp. 341-362). Brasília: UnB.

Lemgruber, J. (2001). Controle da criminalidade: mitos e fatos. Revista Think Tank. Instituto Liberal do Rio de Janeiro, Centro de Estudos de Segurança e Cidadania da 
Universidade Cândido Mendes (CeSeC/UCAM). Retirado em 20 de setembro de 2012, de http://www.cesec_ ucam.com.br

Lohan, J. A., \& Murphy, S. A. (2002). Family functioning and family typology after adolescent or young adult's sudden violent death. Journal of Family Nursing, 8, 3249.

Machado da Silva, L. A. (2011). Polícia e violência urbana em uma cidade brasileira. Etnográfica, 15, 67-82.

Malone, L. (2007). In the aftermath: Listening to people bereaved by homicide. Probation Journal, 4, 383-393.

Mastrocinque, J. M., Metzeger, J. W., Madeira, J., Lang, K., Pruss, H., Navratil, P. K., Sandys, M., \& Cerulli, C. (2014). I'm still left here with the pain: Exploring the healthy consequences of homicide on families and friends. Homicide Studies, 3, 1-24.

Murphy, S. A. (2006). Evidence-based interventions for parents following their children's violent death. Em E. $\mathrm{K}$. Rynearson (Org.), Violent death: Resilience and intervention beyond the crisis (pp. 175-194). New York: Routledge.

Peres, M. F. T., Cardia, N., \& Santos, P. C. (2006). Homicídios de crianças e jovens no Brasil: 1980-2002 (Relatório Institucional, s.n.). Núcleo de Estudos da Violência-NEV, Universidade de São Paulo. Retidado em 20/08/2012, de http// www.nevusp.org

PNUD-Programa das Nações Unidas para o Desenvolvimento Humano (2010). A verdadeira riqueza das nações: vias para o desenvolvimento humano. Relatório de Desenvolvimento Humano-2010. Retirado em 25/07/ 2012, de http:// www.pnud.org.br

Porto, M. S. G. (2010). Sociologia da violência: do conceito às representações sociais. Brasília: Francis.

Salloum, A., \& Rynearson E. K. (2006). Family resilience after violent death. Em E. K. Rynearson (Org.), Violent death: Resilience and intervention beyond the crisis (pp. 47-63). New York: Routledge.

Soares, G. A. D., Miranda, D, \& Borges, D. (2006). As vítimas ocultas da violência na cidade do Rio de Janeiro. Rio de Janeiro: Civilização Brasileira.

Sharpe, T. L. (2015). Understanding the sociocultural context of coping for African American family members of homicide victims: A conceptual model. Trauma, Violence \& Abuse, 16(1), 48-59.

Spungen, D. (1998). Homicide: The hidden victims - a guide for professionals. London: Sage.

UN-Habitat-United Nations Human Settlements Programme (2008). State of the world's cities. London: Earthscan

Vasconcelos, A. M. N., \& Costa, A. (2005). Demografia da violência no Distrito Federal: evolução e características. Em A. Paviani, I. C. B. Ferreira, \& F. F. P. Barreto (Orgs.), Brasília: dimensões da violência urbana (pp. 33-56). Brasília: UnB.

Zilli, L. F. \& Vargas, J. D. (2013). O trabalho da polícia investigativa face aos homicídios de jovens em Belo Horizonte. Ciência \& Saúde Coletiva, 18(3), 621-632.

Waiselfisz, J. J. (2007). Relatório de desenvolvimento juvenil. Instituto Sangari, Ministério da Ciência e Tecnologia (MCT). Brasília: RITLA

Waiselfisz, J. J. (2008). Mapa da violência: os jovens da América Latina: Brasília: OEI.

Waiselfisz, J. J. (2011). Mapa da violência 2011. Os jovens do Brasil. São Paulo: Instituto Sangari.

Waiselfisz, J. J. (2012). Mapa da violência 2012: Os novos padrões da violência homicida no Brasil. São Paulo: Instituto Sangari.

Waiselfisz, J. J. (2013a). Mapa da violência 2013: Homicídios e violência no Brasil. São Paulo: Instituto Sangari.

Waiselfisz, J. J. (2013b). Mapa da violência 2013: Mortes matadas por armas de fogo. Rio de janeiro: FLACSO/ CEBELA.

Waiselfisz, J. J. (2015). Mapa da violência 2015: Mortes matadas por armas de fogo. Brasília: Secretaria Geral da Presidência da República e UNESCO. Disponível em www.mapadaviolencia.org.br

Walsh, F. (2006). Strengthening family resilience ( $2^{\mathrm{a}}$ ed.). New York: The Guilford Press.

\section{Nota:}

1 A pesquisa contou com o apoio financeiro da Coordenação de Aperfeiçoamento de Pessoal de Nível Superior - CAPES, e é fruto da dissertação da primeira autora, orientada pela segunda. 